\title{
O ensino da cor nos livros didáticos de Arte
}

The teaching of color in Art textbooks

Milena Quattrer, Mestra, Universidade Estadual de Campinas, mquattrer@gmail.com;

Anna Paula Silva Gouveia, Doutora, Universidade Estadual de Campinas, annagouveia@iar.unicamp.br;

\section{Resumo}

O artigo se preocupa em comparar e analisar os conceitos apresentados pelos livros didáticos de Arte para o Ensino Fundamental no que diz respeito à teoria da cor, especificamente naqueles publicados no Brasil entre os anos 2000 e 2015 pelos grupos Abril, Santillana, IBEP, FTD e Ediouro.

Palavras Chave: cor, livro didático, arte/educação.

\section{Abstract}

This article aims at comparing and analyzing the concepts presented by Art textbooks for primary education regarding to the theory of color, especially those published in Brazil between 2000 and 2015 by Abril, Santillana, IBEP, FTD and Ediouro.

Keywords: color, textbook, art education. 


\section{Introdução}

Para se discutir e analisar os conceitos de teoria da cor apresentados pelos livros didáticos de Arte, é preciso compreender o quadro atual do ensino de Arte no Brasil. Apesar das ações e movimentos que se sucederam nas últimas décadas tanto por iniciativa de arte/educadores quanto por esferas governamentais, como é o caso dos Parâmetros Curriculares Nacionais (PCNs), o que se vê atualmente nas escolas brasileiras se aproxima da prática do início dos anos 1970: professores polivalentes responsáveis por trabalhar com os alunos as quatro linguagens.

Outro agravante é a inexistência de um espaço adequado para o ensino de Arte em grande parte das escolas da rede pública. Mognol citada por Silva destaca a importância da

(...) instalação de laboratórios de linguagens artísticas com disponibilidade de recursos materiais, físicos e de equipamentos adequados à percepção, ao estímulo e ao significado para o aluno. Espaços flexíveis e versáteis possibilitadores da criatividade, da ludicidade, da interação e do respeito à diversidade, sem esquecer-se do espaço externo. (MOGNOL Apud SILVA, [s.d], p.10)

Diante desse quadro, que envolve desde a prática da polivalência à falta de espaço adequado ao ensino de Arte, observa-se que o livro didático ainda hoje é um recurso importante nas aulas de Arte, seja na rede particular ou na rede pública. Nesta última, em especial, apesar de não ser oficialmente adotado no ensino fundamental por programas como o Plano Nacional do Livro Didático (PNLD)ii, o livro didático de Arte é facilmente encontrado nas bibliotecas das escolas, mais precisamente localizado entre os materiais didáticos oferecidos como suporte prático e teórico às aulas de Arte.

\section{Livro didático}

Por livro didático entende-se "o livro que vai ser utilizado em aulas e cursos, que provavelmente foi escrito, editado, vendido e comprado, tendo em vista essa utilização escolar e sistemática. ${ }^{\text {"iii }}$ Apesar dos crescentes investimentos em 'Tecnologia da Informação e Comunicação' (TIC), na educação brasileira, os livros didáticos impressos ainda têm um papel muito importante na produção, circulação e apropriação do conhecimento. Em situações de extrema precariedade, nas quais se encontram algumas unidades escolares brasileiras, o livro didático, muitas vezes, acaba, segundo Lajolo, "determinando conteúdos e condicionando estratégias de ensino, marcando, pois, de forma decisiva, o que se ensina e como se ensina o que se ensina" (LAJOLO, 1996, p.4) ${ }^{\mathrm{iv}}$. Ainda segundo a autora,

Todos os componentes do livro didático devem estar em função da aprendizagem que ele patrocina. Como um livro não se constitui 
apenas de linguagem verbal, é preciso que todas as linguagens ${ }^{v}$ de que ele se vale sejam igualmente eficientes. $O$ que significa que a impressão do livro deve ser nítida, a encadernação resistente, e que suas ilustrações, diagramas e tabelas devem refinar, matizar e requintar o significado dos conteúdos e atitudes que essas linguagens ilustram, diagramam e tabelam. (LAJOLO, 1996, p.5)

Pesquisadores brasileiros têm se preocupado com o livro didático, Machado (1996, p.31), em especial, reflete sobre quatro pontos centrais no processo de produção e análise do livro didático: qualidade, quantidade, custo e atualização. Segundo o autor,

\begin{abstract}
Após um curto período de predomínio, o livro "consumível" foi "condenado" por razões essencialmente econômicas, permanecendo ao largo os fatores pedagógicos mais incisivos que o tornavam indesejável. A forma básica de utilização, no entanto, foi mantida, e o livro "adotado" pelo professor-consumível ou não - praticamente determina o conteúdo a ser ensinado. O professor abdica do privilégio de projetar os caminhos a serem trilhados, em consonância com as circunstâncias - experiências, interesses, perspectivas - de seus alunos, passando a conformar-se, mais ou menos acriticamente, com o encadeamento de temas propostos pelo autor. Tal encadeamento ora tem características idiossincráticas, ora resulta da cristalização de certos percursos, que de tanto serem repetidos, adquirem certa aparência de necessidade lógica; nos dois casos, a passividade do professor torna um pouco mais difícil a já complexa tarefa da construção da autonomia intelectual dos alunos.
\end{abstract}

Desse modo, o livro didático caracteriza-se como um importante recurso no processo de ensino e aprendizagem. Principalmente no que diz respeito ao ensino de arte, caracterizado pela prática da polivalência. No entanto, a sua adoção é um assunto polêmico.

Ferraz e Siqueira (1987), em pesquisa realizada no estado de São Paulo, levantaram o debate do uso/adoção ou não dos livros didáticos para o ensino de arte e concluíram que, tendo em vista os propósitos deste ensino, 'ela [a arte] opõe-se frontalmente ao livro didático, que é estático, geralmente reducionista, cerceador da liberdade'. (TOURINHO; COSTA, 2008, p.205)

Em 1983, Barbosa (2012, p.11) entrevistou 2.500 professores de educação artística da rede pública de São Paulo e, segundo a autora, todos "mencionaram o desenvolvimento da criatividade como primeiro objetivo de seu ensino". Entretanto, ainda segundo a autora, a pesquisa de Heloísa Ferraz e Idméa Siqueira realizada entre 1983 e 1985 apontou que 82,8\% dos professores de arte entrevistados indicaram o livro didático como sua fonte de ensino. 
Isso parece uma contradição porque os livros didáticos para arte/educação são apenas modernizações na aparência gráfica de livros didáticos usados no ensino de desenho geométrico nos anos de 1940 e 1950, sem nenhuma preocupação com a autoliberação - objetivo que os professores de arte da primeira pesquisa deram como prioridade de seu curso. (BARBOSA, 2012, p.11-12)

Os dados citados por Barbosa somados à experiência da prática docente na Rede Municipal de Ensino de Campinas e aos levantamentos realizados para a pesquisa de Doutorado da qual este artigo é fruto, permitem afirmar que o professor utiliza o livro didático de Arte em suas aulas como fonte de consulta e apoio às aulas teóricas e práticas. Nas aulas sobre conteúdos dos quais não tem pleno domínio, como é o caso dos conceitos de teoria da cor, o livro didático se torna o principal referencial teórico.

Chamamos a atenção para esse ponto, uma vez que, como pesquisadora e professora de Arte do ensino fundamental, observo na grande maioria dos livros didáticos de arte disponíveis no mercado brasileiro, nas bibliotecas das escolas e nos acervos pessoais de colegas de profissão, problemas conceituais no que diz respeito ao ensino da cor ou mesmo a apresentação de conteúdo e propostas de ensino e aprendizagem cristalizados.

\section{A cor no componente curricular Arte}

No que diz respeito à cor no componente curricular Arte, os PCNs a relacionam entre os elementos básicos da linguagem visual: ponto, linha, plano, cor, textura, forma, volume, luz, ritmo, movimento, equilíbrio, que, por sua vez, são parte dos conteúdos gerais de Artes Visuais a serem trabalhados com alunos do ensino fundamental. De acordo com os PCNs (BRASIL, 1997, p.45),

Criar e perceber formas visuais implica trabalhar frequentemente com as relações entre os elementos que as compõem, tais como ponto, linha, plano, cor, luz, movimento e ritmo. As articulações desses elementos nas imagens dá origem à configuração de códigos que se transformam ao longo dos tempos. Tais normas de formação das imagens podem ser assimiladas pelos alunos como conhecimento e aplicação prática recriadora e atualizada em seus trabalhos, conforme seus projetos demandem e sua sensibilidade e condições de concretizá-los permitam. O aluno também cria suas poéticas onde gera códigos pessoais. Além disso, é preciso considerar as técnicas, procedimentos, informações históricas, produtores, relações culturais e sociais envolvidas na experiência que darão suporte às suas representações (conceitos ou teorias) sobre arte. Tais representações transformam-se ao longo do desenvolvimento à medida que avança 0 processo de aprendizagem. 
Autores como Rossi (2009) e a prática docente apontam que em situações de ensino e aprendizagem que envolvam, por exemplo, a leitura, análise e comparação de imagens produzidas por diferentes culturas ou pelos próprios alunos, a cor aparece como um dos elementos de destaque, mesmo em crianças muito pequenas. Segundo Rossi (2009, p.76),

(...) o critério da cor é usado de diversas maneiras no julgamento estético em todos os níveis de escolarização.

\section{Abordagens teóricas}

Buscou-se em Andrea Frova (2008), Luciano Guimarães (2004) e Anna Paula Silva Gouveia (2009) o respaldo teórico para se discutir os conceitos de teoria da cor apresentados nos livros didáticos analisados.

A partir de estudos como os de Young e Helmholtz sobre a fisiologia da visão definiu-se como primárias de cor-luz (síntese aditiva) três cores: vermelho, verde e azul-violeta; e como primárias de cor-pigmento (síntese subtrativa) outras três cores: magenta, amarelo e ciano (Frova 2008, p.148). É possível observar as sínteses aditiva e subtrativa, respectivamente, nas figuras 1 e 2 .

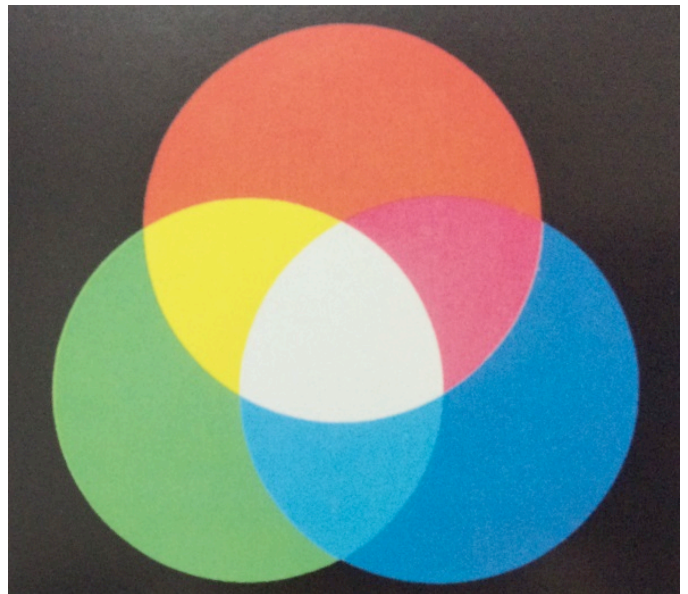

Figura 1: Síntese aditiva. (FROVA, 2008, p.IX) 


\section{V SILID IV SIMAR \\ PUC-Rio - Dias 28, 29 e 30 de julho de 2015}

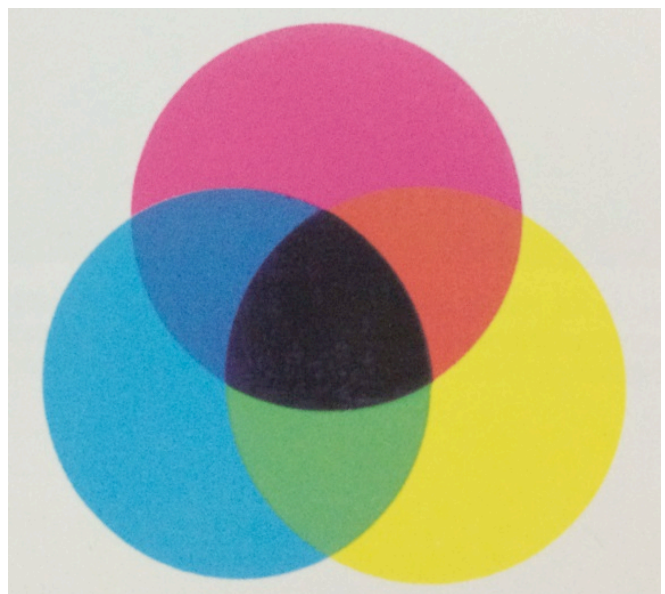

Figura 2: Síntese subtrativa. (FROVA, 2008, p.IX)

Segundo Guimarães (2004, p.54-55),

Os três parâmetros para definição das cores são praticamente universais. Um primeiro para determinar a exata posição da cor no espectro eletromagnético; um segundo para determinar as atenuações ascendentes (clareamento) e descendentes (escurecimento) da cor; e um terceiro para determinar a proximidade da cor espectral com a sua correspondente em uma escala de tons de cinza.

Apesar de universais, os parâmetros de definição da cor recebem denominações e definições diversas.

Segundo Monzeglio (1992), as três dimensões ou atributos da cor, que Guimarães denomina parâmetros, são: matiz (posição espectral), claridade (do matiz mais claro ao mais escuro) e saturação (do matiz mais puro ao mais impuro). (GOUVEIA, 2009)

Sendo assim, para a pesquisa adotou-se os parâmetros de definição da cor: 'matiz', 'claridade' e 'saturação'. Em que 'matiz' corresponde à posição espectral, 'claridade' se refere à variação de clareamento e escurecimento da cor, e 'saturação' à variação da cor em uma escala que parte do matiz mais puro ao seu tom de cinza correspondente.

\section{Métodos}

Para o presente texto optou-se por realizar os seguintes procedimentos metodológicos:

I. levantamento dos livros didáticos direcionados ao ensino e aprendizagem de Arte no ensino fundamental I, publicados no Brasil entre os anos de 2000 e 2014; 
II. seleção dos livros didáticos que apresentem conceitos relativos à teoria da cor;

III. comparação e análise dos conceitos apresentados pelos livros didáticos selecionados no que diz respeito à teoria da cor.

\section{Levantamento dos livros didáticos de Arte}

A seguir, em ordem cronológica de publicação, estão elencadas as coleções de livros didáticos selecionadas para comparação e análise dos conceitos relativos à teoria da cor apresentados. Com exceção da coleção 'Criança e arte: descobrindo as artes visuais', composta por quatro volumes destinados ao segundo, terceiro, quarto e quinto ano, as outras quatro coleções são compostas por cinco volumes, cada um deles destinado a um dos cinco anos do ensino fundamental I. Todas as coleções analisadas são exemplares do professor.

\begin{tabular}{lll} 
Título & Local e Editora & Ano \\
Criança e arte: descobrindo as artes visuais & São Paulo: Ática & 2006 \\
Presente arte & São Paulo: Moderna & 2012 \\
Arte de fazer arte & São Paulo: Saraiva & 2013 \\
Marcha da criança & São Paulo: Scipione & 2013 \\
Mundo melhor arte & $\begin{array}{l}\text { São Paulo: Quinteto } \\
\text { Editorial }\end{array}$ & 2013 \\
\hline
\end{tabular}

Tabela 1: coleções de livros didáticos selecionadas para comparação e análise dos conceitos relativos à teoria da cor apresentados.

\section{Comparação e análise conceitos apresentados pelos livros didáticos relativos à teoria da cor}

Partindo-se da hipótese de que o professor utiliza o livro didático de Arte em suas aulas como fonte de consulta e apoio às aulas teóricas e práticas, o que chama a atenção nas análises é que quatro das cinco coleções selecionadas apresentam problemas conceituais no que diz respeito à teoria da cor. Sendo que a coleção 'Arte presente' não apresenta os conceitos de cor primária ou secundária de síntese subtrativa ou aditiva aos alunos em nenhum dos cinco volumes. Destacam-se aqui três pontos importantes.

O primeiro ponto se refere ao fato de que, apesar da cor ser um dos elementos de sintaxe visual mais importantes, sua abordagem conceitual não é constante nas coleções analisadas: (i) em 'Criança e arte: descobrindo as artes visuais', os conceitos são abordados nos quatro volumes que compõem a coleção; (ii) em 'Presente arte', são tratados nos volumes 1, 3 e 4; (iii) em 'Arte de fazer arte' estão nos volumes 2 e 4; (iv) na 'Marcha da criança' são abordados nos 
volumes 2, 3, 4 e 5; (v) e por fim, na coleção 'Mundo melhor' são tratados nos volumes 1 e 2 .

O segundo ponto diz respeito ao fato de que em nenhuma das coleções analisadas apresentar aos alunos a síntese aditiva (cor-luz). Ou seja, ignora-se totalmente nessas coleções que o aluno vivencie cotidianamente a síntese aditiva e seus efeitos. Mesmo ao trabalhar assuntos como vitrais, vídeo-arte ou mesmo artistas como Seurat e Signac. Nessas coleções, o ensino da cor se resume basicamente à síntese subtrativa (figuras 3, 4, 5 e 6).

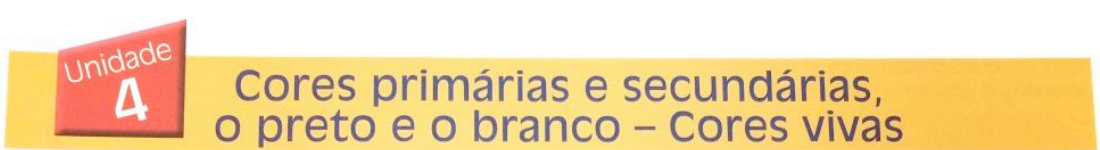

\section{Explorando possibilidades}

Recorte três pedaços de papel celofane nas cores azul, amarela e vermelha.

Coloque o pedaço de papel celofane azul em cima deste quadrado vermelho.

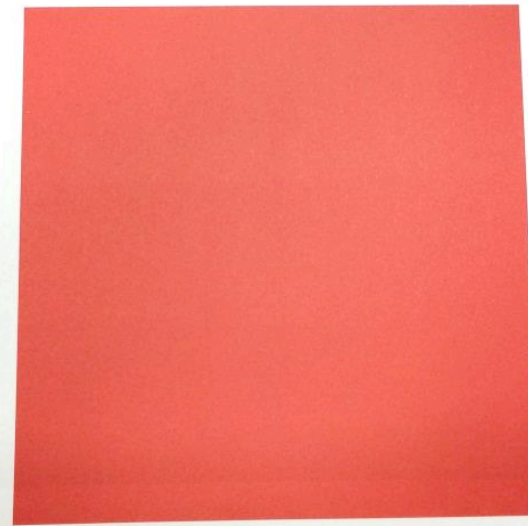

Figura 3: Página 75 do volume 2 da coleção 'Criança e arte'. 


\section{V SILIDIV SIMAR \\ PUC-Rio - Dias 28, 29 e 30 de julho de 2015}

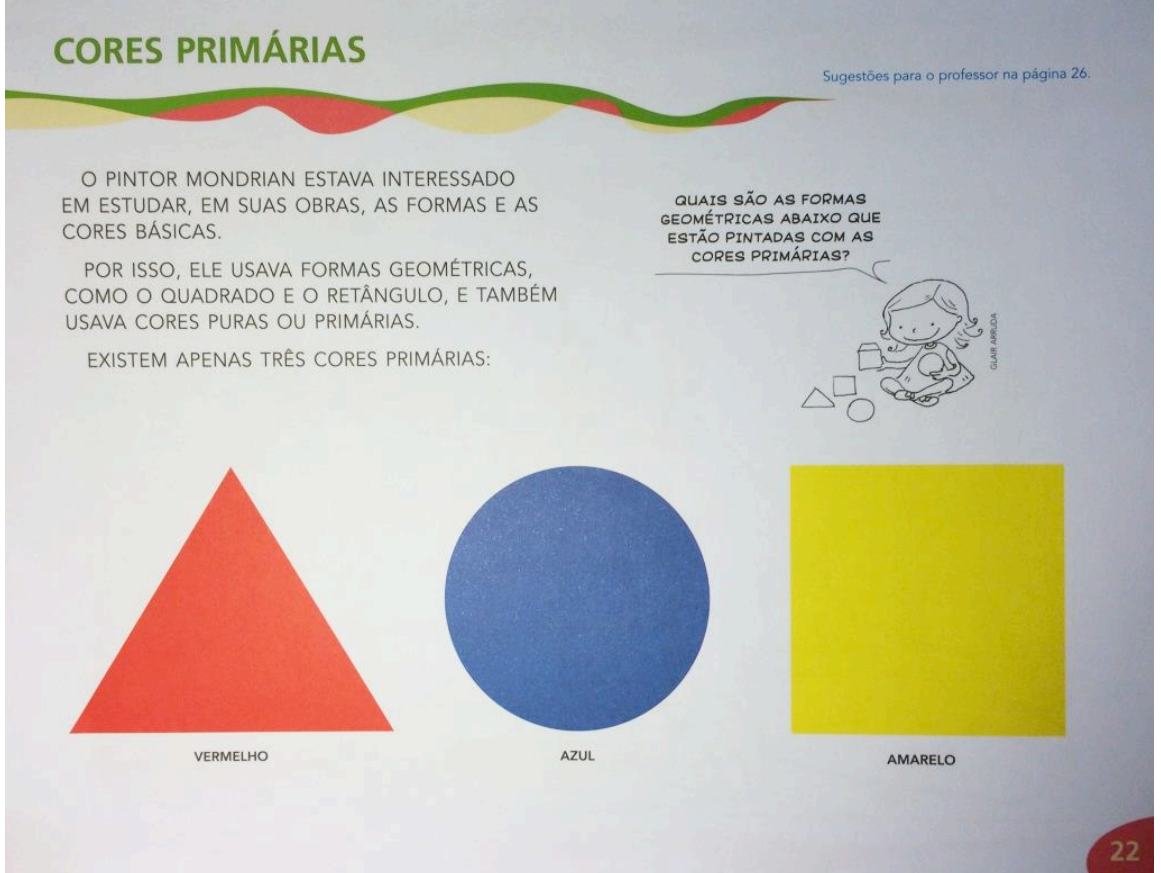

Figura 4: Página 22 do volume 4 da coleção 'Arte de fazer arte'.

As cores vermelha, azul e amarela são conhecidas como cores primárias ou puras, pois não são formadas da mistura de outras cores.

Recorte pedaços de papel celofane e cole-os no quadro da cor correspondente.
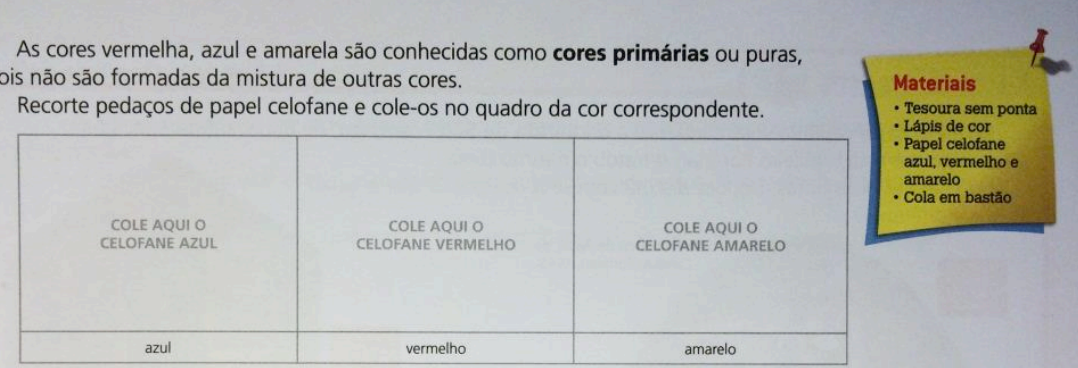

As cores violeta, laranja e verde são chamadas de cores secundárias porque são feitas da mistura de duas cores primárias.

Para ver como isso acontece, cole pedaços de papel celofane nas cores indicadas nos espaços abaixo, uma sobre a outra. Depois, pinte com lápis de cor os quadrinhos abaixo na cor que surgiu dessa mistura.

\begin{tabular}{|c|c|}
\hline $\begin{array}{c}\text { COLANDO O CELOFANE } \\
\text { AZUL + VERMELHO }=\end{array}$ & violeta \\
\hline $\begin{array}{c}\text { COLANDO O CELOFANE } \\
\text { VERMELHO + AMARELO }=\end{array}$ & laranja \\
\hline COLANDO OCELOFANE \\
AZUL + AMARELO $=$
\end{tabular}

Figura 5: Página 81 do volume 2 da coleção 'Marcha da criança'. 


\section{V SILID IV SIMAR

3. Complete o nome da cor de cada um dos lápis.

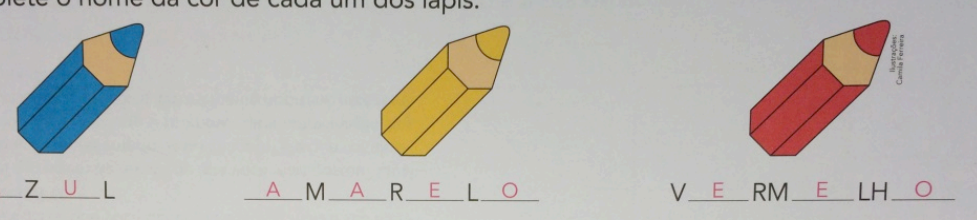

Agora, usando lápis de cor, misture as cores indicadas e observe as novas cores que surgirão.

A

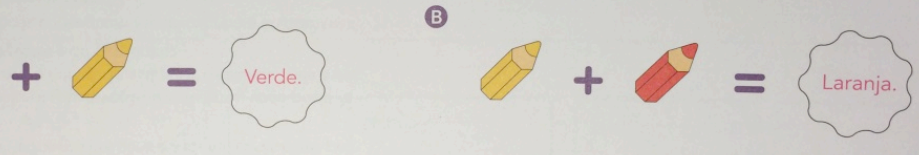

c

Figura 6: Página 46 do volume 1 da coleção 'Mundo melhor'.

O terceiro ponto trata dos erros conceituais acerca da síntese subtrativa. Como foi possível observar nas figuras 3, 45 e 6, o vermelho, nessas coleções, é apresentado aos alunos como cor primária de síntese subtrativa; o magenta sequer é citado nas coleções. Do mesmo modo ocorre com o azul, também erroneamente relacionado entre as cores primárias de síntese subtrativa; do mesmo modo que o magenta, o ciano não é abordado nos livros, mas o pigmento equivalente ao matiz ciano é aplicado em algumas coleções sob a denominação de azul.

$\mathrm{Na}$ coleção que não apresenta erros conceituais, 'Arte Presente', destacamos o volume 1 que aborda os parâmetros de definição da cor. Nesse volume, o texto do infográfico chama a atenção para a variação de tonalidade (que para o presente texto corresponde a matiz), no entanto, na tabela do infográfico a variação de claridade é indicada com auxílio das palavras 'claro' e 'escuro' em negrito e da seta horizontal (figura 7). A sugestão neste caso seria o uso da expressão 'variação de tons' e, principalmente, de uma seta na vertical, de modo a facilitar a compreensão dos alunos dessa faixa etária. 


\section{V SILID IV SIMAR}

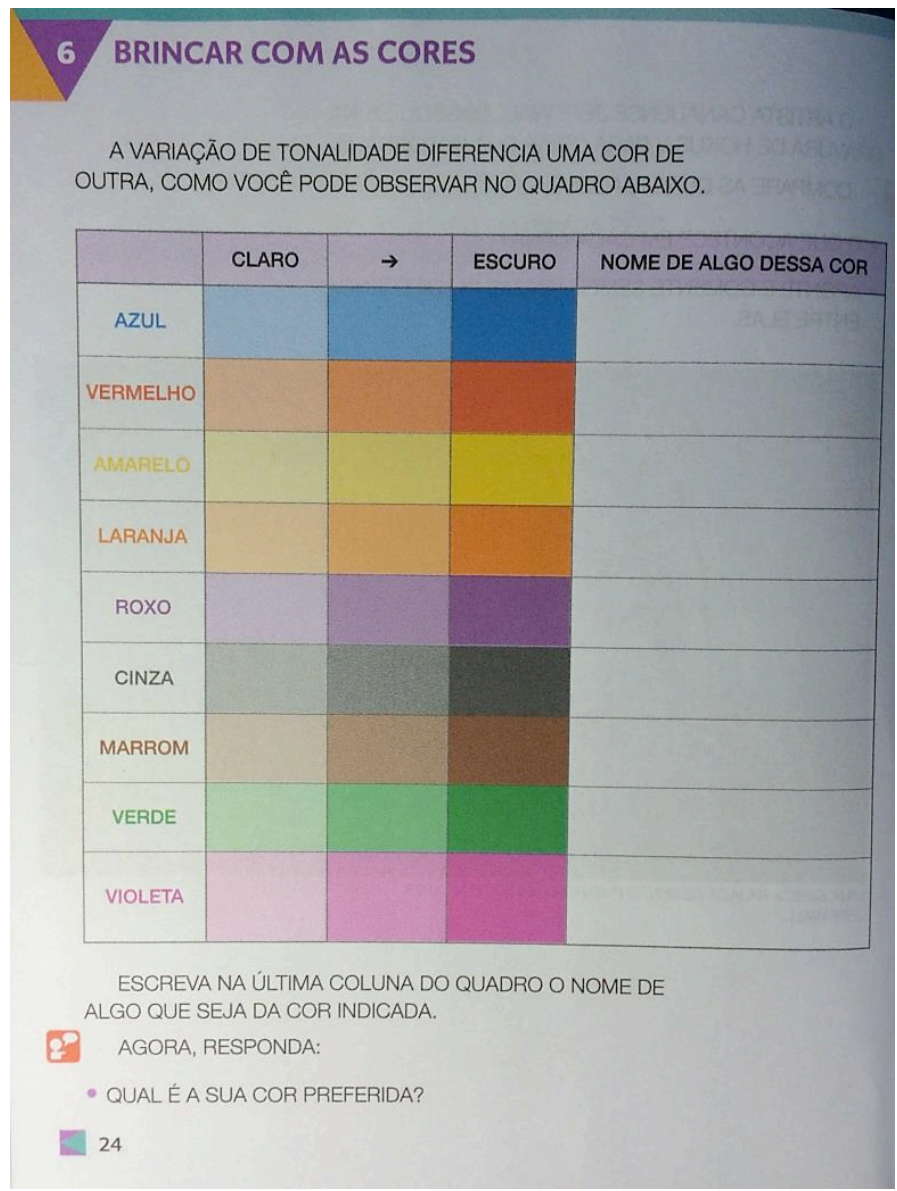

Figura 7: Página 24 do volume 1 da coleção 'Presente arte'.

Ainda sobre os parâmetros de definição da cor, as coleções 'Marcha da criança' e 'Arte de fazer arte', apresentam erros conceituais. Na página 67 do volume 3 da 'Marcha da criança' (figura 8) é empregado o termo 'tom' para indicar variação de claridade, o que está incorreto. No texto que acompanha o infográfico é colocado "Nos dois casos temos vários tons de uma mesma cor, ou seja, uma monocromia"vii. O correto seria dizer que nos dois casos há variação de claridade de um mesmo matiz (ou no caso do termo empregado, do mesmo tom). Do mesmo modo ocorre na página 29 do volume 2 de 'Arte de fazer arte' (figura 9). 


\section{V SILID IV SIMAR \\ PUC-Rio - Dias 28, 29 e 30 de julho de 2015}

\section{Os tons claros e os tons escuros}

Você já aprendeu que as cores primárias são: vermelho, azul e amarelo.

E que quando misturamos duas cores primárias temos as cores secundárias: violeta, verde e laranja Observe o círculo abaixo:

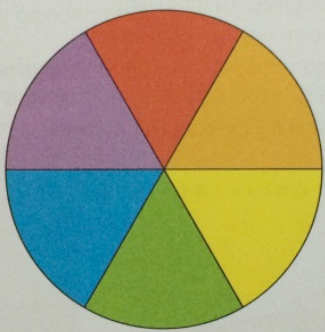

Quando temos uma única cor e a ela acrescentamos a cor branca ou preta, conseguiremos vários tons dessa cor. Por exemplo, se colocarmos umas gotinhas de branco em um pouco de tinta vermelha e misturarmos com o pincel, o vermelho ficará mais claro. Se acrescentarmos cada vez mais tinta branca nessa mistura, podemos obter a cor rosa.

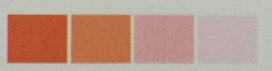

Mas se acrescentarmos um pouquinho de preto na tinta vermelha, ela vai se tornando um marrom avermelhado.

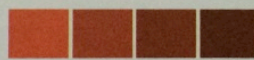

Nos dois casos, temos vários tons de uma mesma cor, ou seja, uma monocromia.

Figura 8: Página 67 do volume 3 da coleção 'Marcha da criança'.

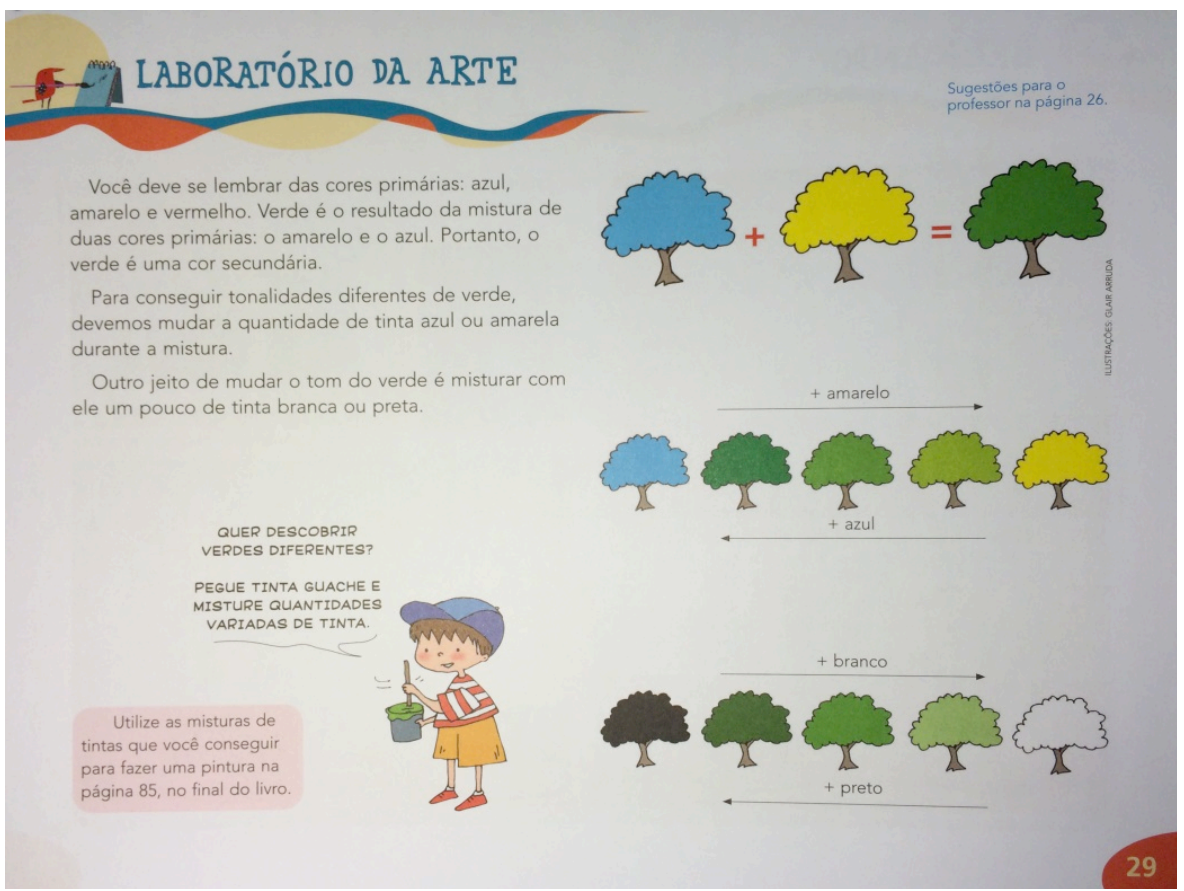

Figura 9: Página 29 do volume 2 da coleção 'Arte de fazer arte'. 


\section{Considerações}

A partir da análise dos livros didáticos de arte destinados ao ensino fundamental, contatou-se que grande parte deles apresenta problemas conceituais no que diz respeito ao ensino da cor. Desse modo, é possível afirmar que o livro didático de arte está desatualizado ou em pouca sintonia com as circunstâncias e as necessidades atuais. Acredita-se que os apontamentos levantados no texto podem contribuir significantemente para o aprimoramento dos livros didáticos de arte e, consequentemente, na formação dos indivíduos aos quais essas coleções atingem.

\section{Referências Bibliográficas}

BRASIL. Secretaria de Educação Fundamental. Parâmetros Curriculares Nacionais: Arte: Ensino de primeira à quarta série. Brasília: MEC/SEF, 1997.

FROVA, A. Luce, colore, visione: perchè si vede ciò che si vede. Milano: BUR Scienza, 2008.

GOUVEIA, A. P. S. Teoria da cor: modulação e escalas. 2009. Slide. Notas de aula.

GUIMARÃES, L. A cor como informação. São Paulo: Annablume, 2004.

i A década de 1970 é marcada pela inclusão obrigatória da arte no currículo escolar, sob o título de Educação Artística, em estabelecimentos de $1^{\circ}$ e $2^{\circ}$ grau através da Lei de Diretrizes e Bases da Educação Nacional - LEI N. 5.692, de 11 de agosto de 1971. Essa lei estabeleceu no ensino de arte a prática da polivalência - o que significou que um mesmo professor passou a ser responsável por ensinar os conteúdos referentes às artes plásticas, música e artes cênicas (teatro e dança) a alunos de primeiro grau (BARBOSA; COUTINHO, 2011, p.28).

ii Programa do governo federal brasileiro de distribuição de livros didáticos aos alunos de educação básica da rede pública.

iii LAJOLO, 1996, p.4.

iv Grifo no original.

v A linguagem visual é uma das linguagens que constitui o livro didático e, assim como a verbal, a linguagem visual é composta de códigos aprendidos e ensinados pelo homem, desde o seu nascimento, e faz parte daquilo que, de acordo com Gonzalo Peltzer (1991, p.27), seria mais apropriado denominar de 'cultura visual'. Pesquisas anteriores demonstraram que o significado dos códigos visuais pode variar de acordo com 0 repertório do emissor e do receptor, bem como do contexto em que esses códigos se encontram.

vi A FTD, editora que atualmente faz parte do Grupo Marista, é sócia controladora da Quinteto Editorial.

vii Grifo no original. 